\title{
TRANSFORMACIONES DE SANTA SUSANA Y LA ALAMEDA EN SANTIAGO DE COMPOSTELA: CIUDAD Y PATRIMONIO
}

Data recepción: 2014/01/17

Data aceptación: 2014/04/25

Minia Bravo Pintos

Contacto autora: miniabravo@gmail.com

Universidade da Coruña

\section{RESUMEN}

El siguiente artículo trata sobre las transformaciones del monte de Santa Susana en Santiago de Compostela desde un punto de vista patrimonial, donde se fusionan contribuciones de distintos campos, ya que el "patrimonio" es el compendio de valores, aportaciones y conocimiento sobre el tema. En Santa Susana no sólo se encuentran un conjunto de edificaciones de gran valor histórico-artístico, sino que la importancia del lugar también reside en el espacio como fuente histórica. Santa Susana es un emplazamiento cuya historia está unida a la de la ciudad pero que corre de manera paralela a ella, ya que no ha seguido las pautas de la "ciudad urbana", preservando en su interior unos valores naturales, espaciales y patrimoniales únicos en su entorno.

Palabras clave: Santa Susana, Santiago de Compostela, valor patrimonial, parque urbano

\begin{abstract}
The following article analyses the transformations that have taken place on Santa Susana hill in Santiago de Compostela in terms of heritage, and brings together a number of contributions from different fields. "Heritage" should be understood as a combination of values, contributions and knowledge of a specific topic. Home to a number of buildings of great historical and artistic importance, Santa Susana hill is also valuable as a historical source. Though closely linked to that of the city itself, its history runs parallel to it. It does not conform to the pattern of an "urban city", preserving in its interior natural, spatial and heritage values that are unique in its environment.
\end{abstract}

Keywords: Santa Susana, Santiago de Compostela, heritage value, city park

En el siguiente trabajo se estudian las transformaciones del monte de Santa Susana desde el siglo XII hasta mediados del XX. Este período comienza con el depósito de los restos de Santa Susana en el Otero de Potros, y concluye con la construcción de los principales edificios de la Residencia de Estudiantes. El estudio trata de comprender cómo la forma de entender y actuar en el espacio ha cambiado con él. Su ocupación comenzó con unas construcciones puntuales que concentraban el valor patrimonial del lugar, lo que cambió en el siglo XVIII cuando se comenzó a concebir el propio espacio como patrimonio. Debido a este cambio de perspectiva el trabajo se divide en dos partes: "Los primeros elementos patrimoniales" y "El espacio como patrimonio".

\section{Los primeros elementos patrimoniales}

El lugar de estudio es un pequeño monte situado al suroeste de Santiago, fuera de la ciudad medieval, un área privilegiada para el control del lateral oeste, estando su cima unos diecisiete metros por encima del nivel de acceso a la ciudad.

El monte, conocido como "Outeiro dos/as Poldros/as"1, contaba con una pequeña capilla de origen románico en la cima. Precisamente esa capilla fue el origen del "monte de Santa Susana" al ser elegida por el arzobispo Xelmírez para cobijar los restos de la Santa². Así en 1105 se inició el culto, y el camino de unión entre la capilla y la ciudad adquirió peso propio (Fig. 1). La 


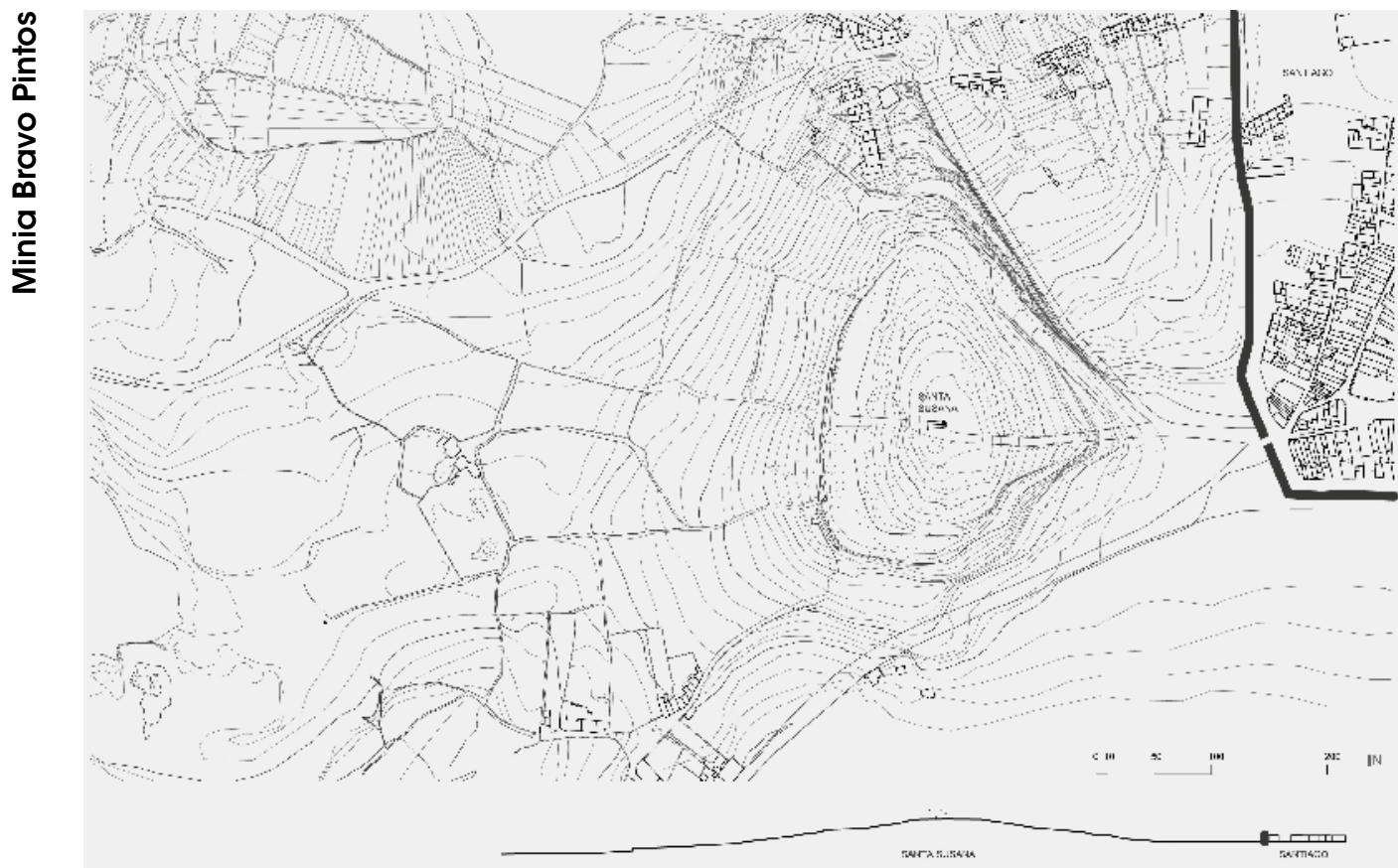

Fig. 1. Reconstrucción del plano y de la sección del monte de Santa Susana, ca. 1.100, apoyado en la planimetría antigua conservada de la ciudad.

única construcción que ha sido testigo de toda la vida del "monte de Santa Susana" es la capilla, acompañada por momentos de otras construcciones $^{3}$. La iglesia y el camino son las huellas de la ocupación medieval del monte.

Con el transcurso del tiempo, y posiblemente con las revueltas de los siglos XIV y XV, la iglesia se arruinó. La cesión de los terrenos del monte a la ciudad en 1546 hizo que la iglesia volviese a formar parte de las procesiones de Santiago 4 . En 1602 recibió un gran impulso al ser incluida en el testamento del Arzobispo de San Clemente, y gracias a esta aportación la capilla creció hasta casi duplicar su tamaño original. Treinta años después, en 1633, se procedió a su reparación tras la declaración de ruina de su cuerpo ${ }^{5}$. Con estas actuaciones se aprecia el valor que la iglesia tuvo para la ciudad (Fig. 2).

La existencia del muro perimetral que aislaba el templo y su cementerio, se conoce desde $1783^{6}$, aunque se supone anterior ya que la celebración de funerales está registrada desde finales del siglo XVI, para lo que debía contar con protección. Durante el XIX la iglesia perdió importancia en su entorno permaneciendo aislada en la cima, y no fue hasta finales de siglo cuando se planteó la conexión con el parque ${ }^{7}$. Así en 1903 se construyó la escalera de conexión con el paseo, comenzando con ello a formar parte de su entorno ${ }^{8}$.

Volviendo al conjunto del monte, una vez analizada brevemente la importancia de la iglesia, se tratará ahora el periodo inmediatamente posterior a la fundación del monte. A modo de breve reseña histórica apuntar que Santiago nació como Ayuntamiento entre 1345-479. Durante el siglo XV tuvieron lugar las revueltas irmandiñas que le afectaron con especial crudeza. En 1467 los irmandiños fueron derrotados a las puertas de la ciudad, dato importante ya que habla de intensos enfrentamientos en Santiago y en sus alrededores donde el monte de Santa Susana era un punto estratégico. En 1546 los terrenos del monte de Santa Susana finalmente fueron cedidos a la ciudad por el Conde de Altamira, alcalde de Santiago, con el fin de "que lo 

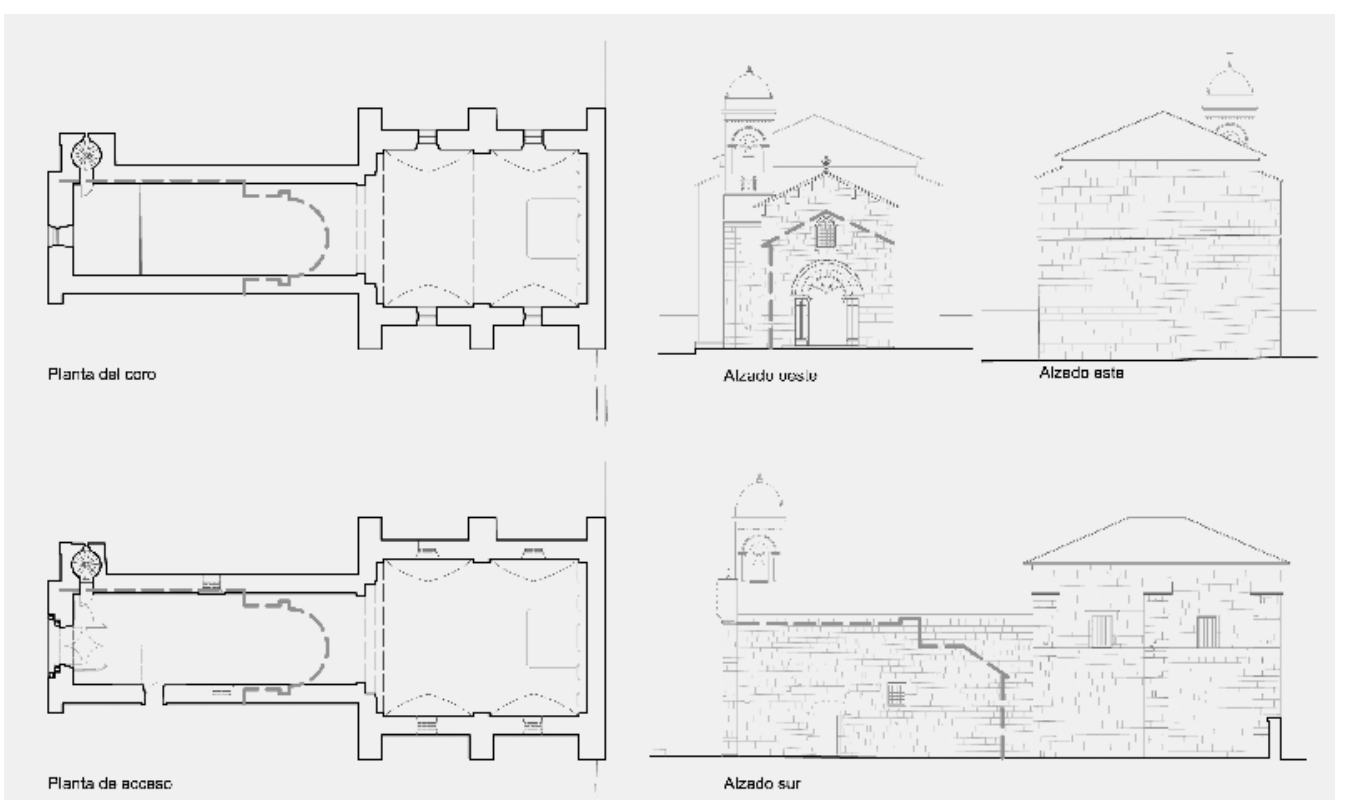

Fig. 2. Planta y alzado de la iglesia de Santa Susana. En línea de trazos gruesa está dibujado el posible perfil de la iglesia románica.

puedan plantar y se tenga por salido y servidumbre de la ciudad" 10.

Como elemento importante del lugar deben mencionarse los usos que ayudaron a definir la personalidad del monte tanto frente a la ciudad como frente a las otras entradas de la muralla. Fue fuente de materias primas desde 1546 (ver cita más arriba), lugar de culto desde el nacimiento del monte como "Santa Susana", y además contó con otra gran variedad de usos ${ }^{11}$ :

1. El uso como lugar de ocio y celebración nació en el siglo XVI y se ha mantenido hasta la actualidad, aunque en sus comienzos no siempre tuvo continuidad ya que dependía del dinero del Ayuntamiento ${ }^{12}$. Se colocaban tiendas y tabernas enfrentándose a la celebración oficial del Apóstol que solía ser en la plaza del Hospital (Obradoiro).

2. Muchos de sus variados usos "residuales" se generaron al entender el monte, en el siglo $\mathrm{XVI}$, como un lugar al servicio de la ciudad a donde poder llevar las actividades que no eran bien acogidas dentro de la muralla ${ }^{13}$.
3. Uno de los usos más importantes, que llegó hasta 1971, fue el de feria de ganado. No se ha encontrado una fecha exacta de creación, pero se ha localizado una mención que podría indicar que se empezó a negociar con mercancías del ganado alrededor de $1552^{14}$. En 1676 se denegó una licencia en el lugar por molestar a la feria de ganado, demostrando la importancia de este uso en el monte ${ }^{15}$. La feria se acabó desplazando hacia la parte superior del monte, provocado por el interés del área inferior como espacio urbano.

4. Al ser Santa Susana un lugar privilegiado en cuanto a situación y elevación respecto de la ciudad, representó un importante lugar defensivo. Un reflejo de este uso, entre otros ${ }^{16}$, es la representación que se hizo del monte en un plano de la ciudad de 1595, donde se planteaba la protección de diferentes elementos, entre ellos Santa Susana ${ }^{17}$.

El cuarto elemento que delimita este espacio, junto con la iglesia, el camino que la unía con la ciudad, y sus usos, fue el camino Real que era la vía que comunicaba Santiago con la ciudad de Pontevedra. 


\subsection{San Clemente como primer elemen- to urbanizador}

Don Juan de San Clemente fue arzobispo de Santiago desde 1587 hasta su muerte en 1602. La construcción de un colegio estuvo perfectamente planeada en su testamento ${ }^{18}$. Cuando se fundó este colegio la ciudad ya contaba con el de Santiago Alfeo (Fonseca), construido entre 1532-48, con el que rivalizó por ser la cabeza intelectual de la ciudad.

El Ayuntamiento cedió el terreno para el colegio, unos diez mil metros cuadrados, en el exterior de la puerta suroeste de la muralla, encontrándose la finca perfectamente definida en $1595^{19}$. La parcela lindaba al sur con el camino medieval, por lo que se puede ver cómo esta vía delimitó la posición de la gran obra renacentista, que comenzó su construcción en agosto de 1605. El colegio afectó a la manera de intervenir en su entorno, ya que al ser una gran construcción de uso cultural su espacio próximo se vio influido por su presencia.

El Ayuntamiento además del terreno concedió en 1608 agua para una fuente. La ciudad empezaba a reclamar agua para los barrios del oeste, ya que contaba únicamente con la fuente de San Miguel, siendo la de San Clemente la primera instalada extramuros. Tal y como se dice en las actas municipales:

por lo que importa al bien común y a la buena memoria del Sr. Arzobispo de San Clemente (...), se le está y concede para (...) el colegio que va fundando, 2 cornados de agua de la fuente de San Miguel (...). Que la fuente (...) se ha de hacer fuera del Colegio en el Campo de delante para que el barrio y vecinos y caminantes gozen de ella ${ }^{20}$.

Su colocación enfrentada a la puerta Real y en línea con la vía a Santa Susana, hizo de ella un elemento de unión entre las edificaciones.

Con el colegio se empezó a entender que el espacio debía tener un significado mayor que el de un ámbito natural, lo que no se logró hasta más de un siglo después. Por ello se denunciaron y derribaron edificacionesy se "desestimaron las pretensiones" de algunos ciudadanos de construir en la puerta ${ }^{21}$. Finalmente estas acciones culminaron en mayo de 1675 con el acuerdo del Ayuntamiento de que "ni ahora ni en ningún tiempo se pueda enajenar ni aforar el sitio de la puerta Faxeira por ser entrada de la ciudad y del Campo de Santa Susana" 22.

Existe una panorámica de Santiago realizada por P.M. Baldi en 1668 desde Santa Susana, donde aparecen el colegio y la fuente en un espacio natural ajeno a la ciudad. Cabe destacar que se optó por no representar la iglesia de Santa Susana, lo que se puede interpretar como que ésta no se entendía como un elemento vinculado a Santiago.

El colegio y el monte, como propiedad de la ciudad, impidieron que la colonización del espacio se produjese de manera similar al de otras vías de salida, haciendo de éste un ámbito único. Así los diferentes usos del colegio se sucedieron en el tiempo haciendo de este punto un lugar singular dentro del conjunto de la ciudad. A modo de resumen de sus usos San Clemente fue colegio de pasantes, 1630 a 1827; seminario conciliar, 1827 a 1882; lugar de acogida del Batallón de Infantería de León, 1808; también se intentó instalar en él la escuela de medicina, 1821; fue facultad de veterinaria y de derecho, de 1885 a 1899; escuela de Artes y Oficios, de 1888 a 1946; tuvo otros usos como: archivo histórico, estación de telégrafos, arqueología, 1871, 1877, 1909; y al fin instituto femenino e Instituto Rosalía de Castro, desde 1940 hasta la actualidad.

Tras la construcción del colegio y su fuente, el espacio extramuros se continuó edificando siguiendo la alineación de la calle de la Senra (al sur de la muralla), respetando así el vacío entre el colegio y la vía a Pontevedra. Esto creó un área libre directamente relacionada con la ciudad, que contaba con suministro de agua. Durante la época en la que se llevó a cabo la construcción del colegio el área siguió cultivando otras construcciones hasta que entró en vigor el acuerdo del Consistorio antes visto.

\subsection{La Capilla de Nuestra Señora del Pilar}

En 1687 se quiso instalar un convento de Cayetanos en la falda del monte, pero no se llegó a ejecutar ${ }^{23}$. En 1703 el canónigo Sánchez Vaamonde pidió licencia para la construcción de la capilla del Pilar, que fue consagrada en $1717^{24}$. La iglesia se situó en uno de los laterales 
del camino, definiendo el área previa a la puerta Faxeira, delimitada ahora más claramente por la propia muralla, San Clemente, el Camino Real y la capilla del Pilar ${ }^{25}$ (Fig. 3).

Continuando con la urbanización del lugar, en febrero de 1742, el Rey concedió "la exacción de quatro maravedies en bara de lienzo y dos en la de estopa, destinados para la fábrica de Quarteles" 26. Así comenzaron las obras del cuartel detrás de la reciente capilla. Existía otro cuartel junto al convento de San Agustín que "por molestar a la vida cotidiana de la comunidad" se quería desplazar, con permiso concedido en 1707, aunque se cree que dicho cuartel aún seguía existiendo en 1741 (Fig. 4). Se supone que se tomó este cuartel como modelo para el de Santa Susana por la proporción de la parcela, su desnivel y por la costumbre en el mundo castrense de repetición tipológica.

El cuartel se completó con una plaza "para instruir a los cabos y sargentos, solear el vestuario y pólvora, (...)" y con otro edificio en la Carrera del Conde. La plaza fue construida, pero se comprobó que era inútil ya que estaba atravesada por la vía Real, por ello en 1788 se solicitó trasladar el patio a detrás del cuartel27. Esta ubicación del cuartel se constata hasta 1814, con su aparición en varios planos del momento, a los que se hará referencia más adelante por presentar importantes datos sobre la urbanización del monte.

\section{El espacio como patrimonio}

Hasta este momento el área de estudio contaba con una serie de elementos independientes enmarcando un área natural. En el siglo XVIII cambió la visión del lugar dejando de ser un grupo de edificios aislados para entenderse en su conjunto. Los primeros intentos de transformar el acceso a la ciudad son de mediados de siglo y, aunque no se llegaron a realizar, acondicionaron el lugar, lo que sirvió de base para plantear otros proyectos.

En 1753 la ciudad comenzó a ordenar el espacio de Santa Susana ${ }^{28}$. Buscaba un lugar de ocio y eligió el monte, probablemente por ser el espacio libre más cercano a la muralla, con una topografía suave y con usos culturales.

En 1780 se aprobaron unas Ordenanzas ${ }^{29}$ que trataban de buscar una mayor salubridad y comodidad de la ciudad, consistían en una serie

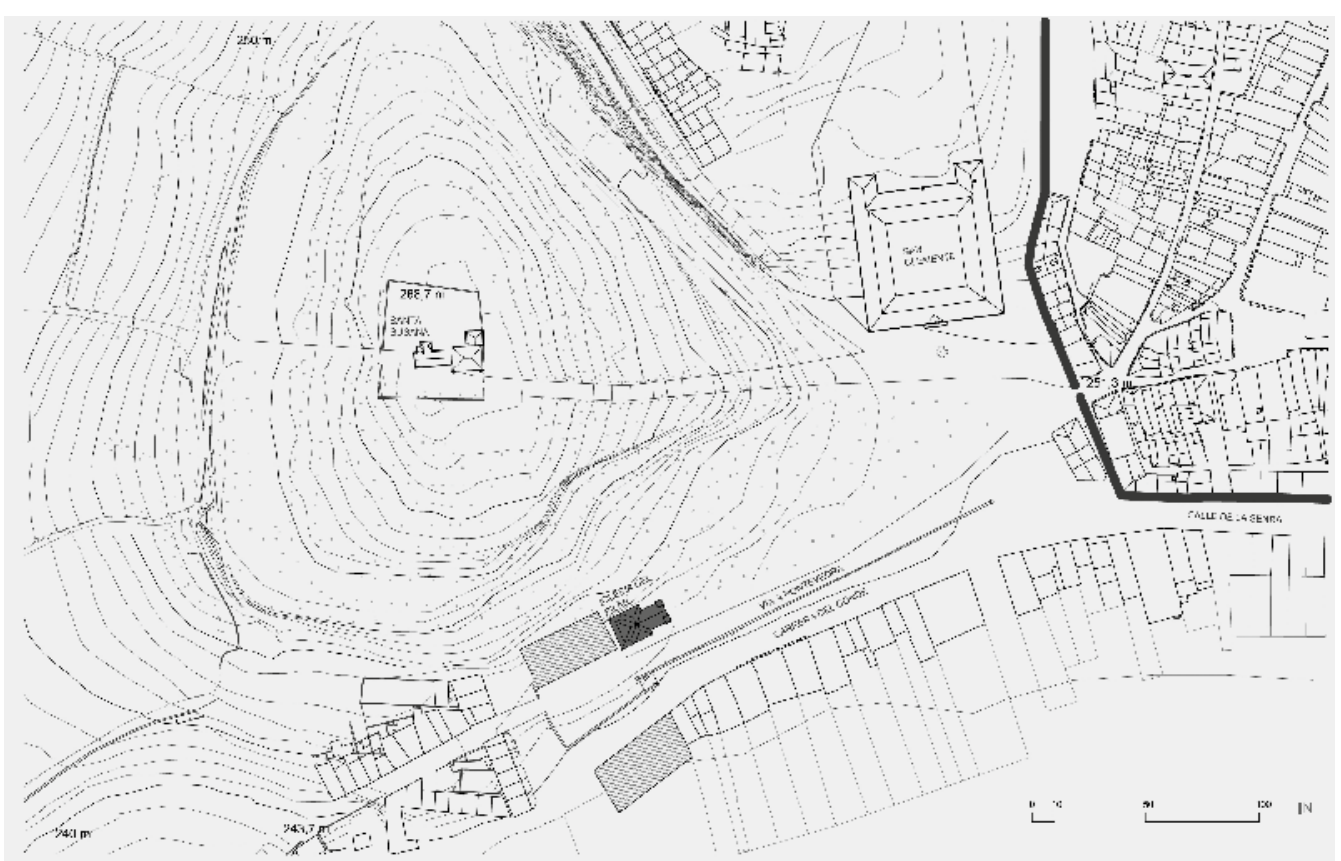

Fig. 3. Reconstrucción del entorno de Santa Susana en 1741. Aparece con sombreado sólido la iglesia de Nuestra Señora del Pilar, y con sombreado de líneas el cuartel. 


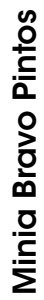
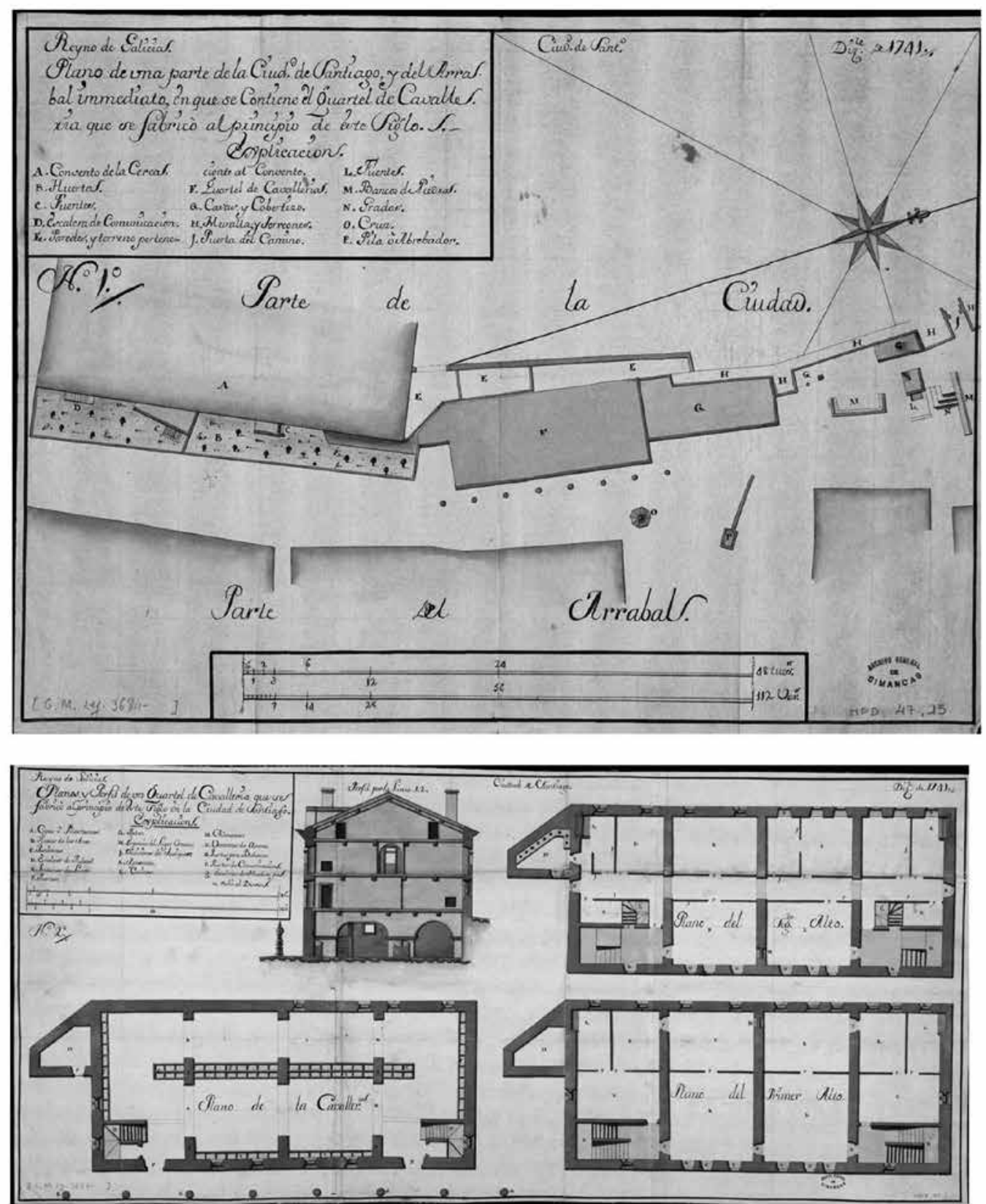

Fig. 4. Planos del Archivo de Simancas. Plano 1, superior: situación del cuartel al lado del convento de la Cerca AGS, 1741, MPD, 47, 015. Plano 2, inferior: Cuartel al lado del convento de la Cerca AGS, 1741, MPD, 44, 003.

de recomendaciones y obligaciones que afectaban a áreas públicas y a construcciones privadas. Aunque fueron muy ambiciosas se limitaron sus intervenciones debido a los grandes gastos que suponían. Concretamente en lo que afectó a Santa Susana "se excluyeron los 678.472 reales para todos los empedrados de los arrabales y entradas de esta ciudad". 
Poco después de la aprobación de las ordenanzas, el 22 de diciembre de 1782 el Capitán General del Reino de Galicia e ingeniero Pedro Martín Cermeño envió a Santiago un proyecto para el espacio entre la puerta Faxeira y la Iglesia del Pilar ${ }^{30}$, delimitando un área de ciento ochenta y ocho por noventa y un metros cuadrados, recibiéndose los planos aprobados por su Majestad en enero de $1783^{31}$. La propuesta fue muy ambiciosa con unas dimensiones mayores que las de la reciente plaza del Obradoiro ${ }^{32}$. El proyecto consistía en la construcción de una gran plaza de entrada a la ciudad, para ello se diseñaron tres edificios: uno que seguía la alineación del Pilar y que incluía al templo en su construcción; y los otros dos en el frente norte, logrando un cierre homogéneo ${ }^{33}$ (Fig. 5). Hubo intención de ejecutar el proyecto ${ }^{34} \mathrm{y}$ aunque finalmente no se realizó sirvió para sentar las bases de la futura ordenación ya que sí se llegó a ejecutar la explanación y el muro de contención en el lado norte, según la línea trazada en el proyecto, y que aún existe hoy en día. Esta intervención generó un importante desnivel al oeste, en el lateral del Pilar, que no se abordó hasta más de medio siglo después.
Tras la aportación de Cermeño Santa Susana era la única salida de la ciudad que presentaba un espacio libre junto a la puerta con apenas dos metros de desnivel en sus doscientos metros de $\operatorname{largo}^{35}$. Así en la solicitud presentada por el Marqués de Bendaña para la formación del patio tras el cuartel en 1788, mencionada antes, aparece claramente delimitado el campo de Santa Susana.

En este espacio se planteó otra urbanización de la que no se tiene más información que la contenida en un plano de $1801^{36}$ donde aparecen unas trazas tímidamente reflejadas (Fig. 6). La plaza definida continuaba con la alineación del Pilar proponiendo una edificación contigua a ella; el frente norte seguía una alineación paralela a la propuesta anterior pero retrasándola hasta el colegio. Las dimensiones proyectadas eran de doscientos metros por algo más de cien. La propuesta fue más allá de la definición del espacio de la "plaza" planteando una ordenación en el monte, quedando así la iglesia de Santa Susana desplazada de su relación con la ciudad.

Así el monte se comenzó a transformar en un área de la ciudad. Tras estas propuestas el

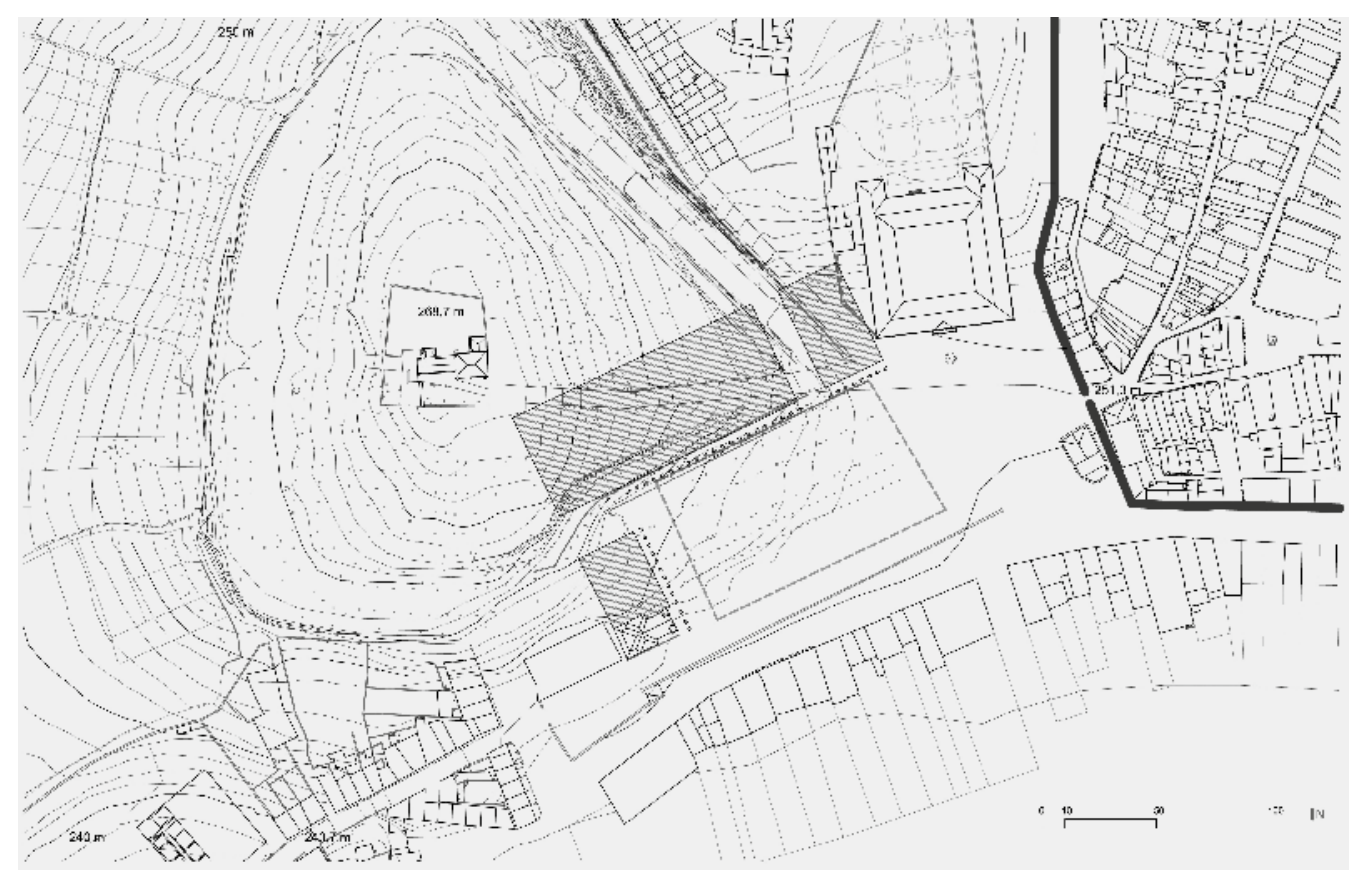

Fig. 5. Plano que refleja la propuesta de Pedro Martín Cermeño (sombreada) junto con la dimensión de la plaza del Obradoiro superpuesta (línea a trazos) sobre una reconstrucción del plano de Santiago de Compostela del año 1782. 


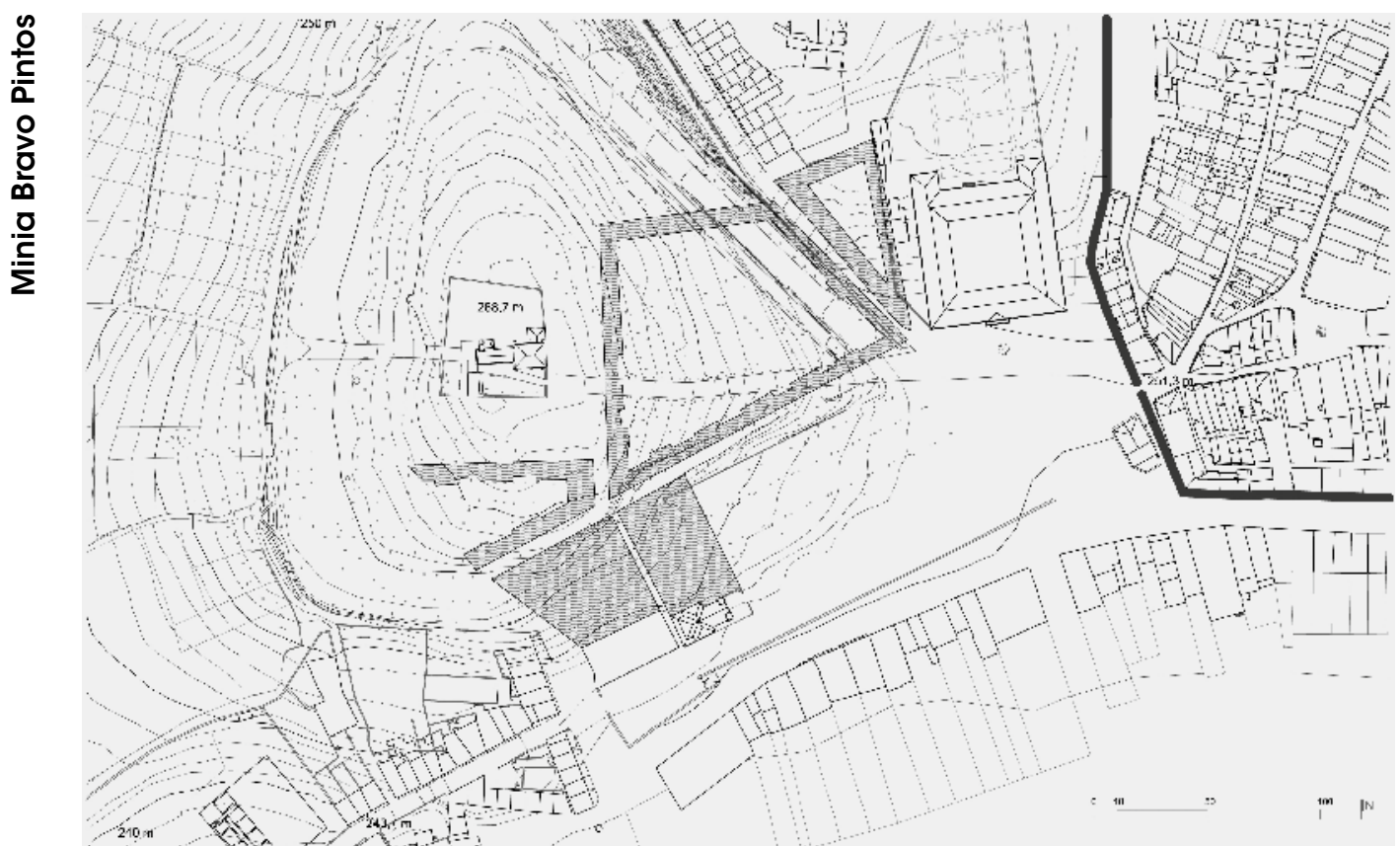

Fig. 6. Plano con propuesta para la urbanización de Santa Susana (sombreada) según trazas del plano conservado en el AHUS [A.M., Gobierno, Consistorios, Libro de Actas 289, $2^{\circ}$ Cuatrimestre de 1801, folio 35r] ca. 1801.

espacio siguió siendo un ámbito natural con un uso cada vez más urbano. Los diseños del XVIII dejaron su huella en la horizontalidad, la forma y la delimitación de la "plaza" con lo que las intervenciones posteriores "sólo" fueron una continuación, aprovechando lo ya ejecutado.

\subsection{Paseo público}

En octubre de 1827 el Ayuntamiento acordó "la necesidad de formar un paseo público" 37. El interés de los terrenos de los bordes de la ciudad se elevó con la demolición de la muralla en 1830. Casi simultáneamente a la demolición se entregó el proyecto de parque de B. Galiano para el monte de Santa Susana, en $1831^{38}$. El proyecto definió una plaza rectangular frente al Pilar de ciento treinta por sesenta metros cuadrados, aprovechando el espacio delimitado en el XVIII, a esta área se le añadía un paseo que bordeaba el monte de casi setecientos metros de largo que incorporaba un mirador al oeste. Por último proponía una conexión directa entre los dos espacios de estancia atravesando el monte por su cima, pero ignorando la iglesia de Santa Susana ${ }^{39}$. Esta propuesta, que sobre el papel parecía muy ambiciosa, realmente no lo era tanto ya que consistía en dar continuidad a los espacios existentes resolviendo sus puntos de encuentro. Cabe destacar que no se tuvieron en cuenta dos elementos básicos del espacio: la iglesia de Santa Susana y San Clemente. De este proyecto, que marcó una pauta a seguir en actuaciones posteriores, no se ha localizado referencia directa sobre su aprobación.

La construcción del parque comenzó con la delimitación de la plaza cercana a la ciudad que, sin ocupar todo el espacio libre, dejaba a un lado el colegio. El 9 de febrero de 1835 comenzaron oficialmente las obras ${ }^{40}$. Ese mismo año se diseñó el cierre y la portada ornamental de los leones enfrentada al acceso a la ciudad, reflejándose su ejecución en las actas del Consistorio en $1837^{41}$. Ese año se proyectó la escalera que conectaba la plaza con el paseo de Buena Vista, también llamado de la Herradura o de Bóveda (perimetral al monte), junto al Pilar, ejecutándose en $1840^{42}$ (Fig. 7). Con esta escalera se acabó de definir el espacio de "la Alameda", quedando reflejado en un dibujo del primer jardinero municipal en $1878^{43}$. La regularización del paseo se llevó a 


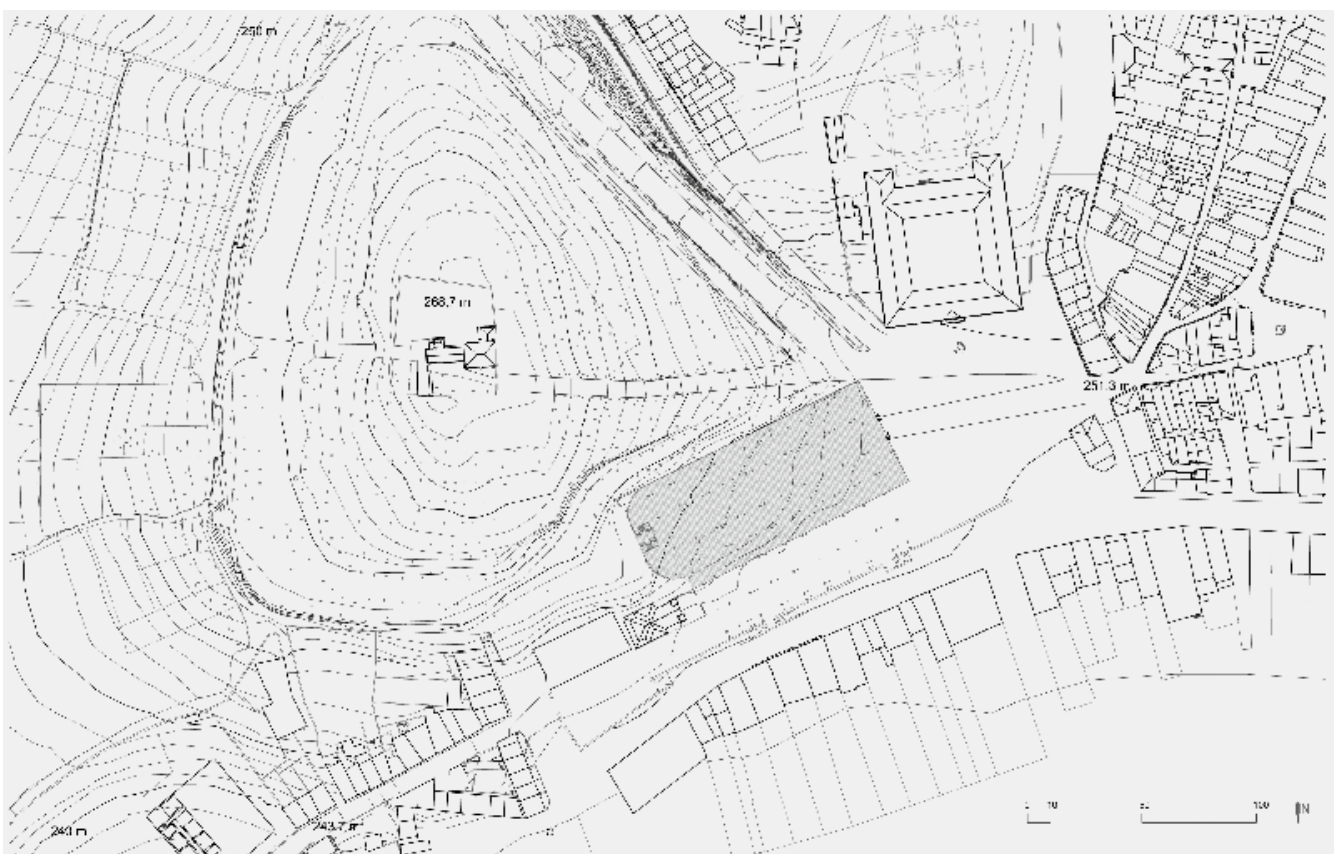

Fig. 7. Plano con las primeras obras realizadas en el parque de la Alameda incluyendo la delimitación del parque (sombreado) y la situación de las Puertas de los Leones en posición central, 1840.

cabo paulatinamente desde 1865 , y debido a la falta de recursos se prolongó hasta el siglo $X X^{44}$. El único camino del proyecto de Galiano que no se llegó a realizar fue el que atravesaba el monte por su cima, quedando como su sustituto el camino medieval existente. En una segunda fase, en 1885, se construyó una verja en el "Salón París" (delante de San Clemente) y se realizaron pequeñas reformas como el ajardinamiento frente al Pilar ${ }^{45}$. Esta alteración produjo un cambio sustancial ya que aumentó las dimensiones del parque y lo acercó a la ciudad.

Llevando el paseo abierto unos cincuenta años, se empezaron a valorar sus vistas y se pidió al Ayuntamiento que evitase "construcciones inmediatas al paseo de la Herradura que cierren vistas a San Lorenzo". Por ello en 1890, se tramitó la expropiación de los terrenos al oeste del monte ${ }^{46}$.

En 1893 se planteó la construcción de la estatua de Figueroa, y tras barajar varias localizaciones se decidió situarla en los jardines del parque, enfrentada a la puerta del colegio, provocando con ello el desplazamiento de la fuente del XVII, que se movió pocos metros, hasta el Campo de la Estrella ${ }^{47}$. La estatua permaneció allí medio siglo (desde 1899) siendo sustituida por la fuente original, que se reinstaló un poco más alejada del colegio que en el siglo XVII. La estatua se ubicó en el paseo de la Herradura en 1949 presidiendo la unión con la Residencia de Estudiantes. La ampliación de los jardines frente al colegio en 1900 definió el espacio casi tal y como lo conocemos hoy ${ }^{48}$ (Fig. 8).

Se intentó que el parque tuviese los servicios adecuados para su uso, y así en 1897 se construyó un Kiosko para música. Para él se plantearon varias localizaciones, optándose por la de clavarlo en el muro norte del parque ${ }^{49}$. También se realizaron otros edificios temporales de pequeño porte que abrieron el abanico de actividades. Por ejemplo en 1901 se solicitó terreno para un cinematógrafo50; en diciembre de 1908 J. Abelleira solicitó permiso para instalar un kiosko para la venta de refrescos ${ }^{51}$; y en 1909, coincidiendo con la exposición Regional, J. Pereira solicitó licencia para instalar un cinematógrafo durante los meses de la exposición (Fig. 9). El espacio se completó con otros elementos como los monu- 


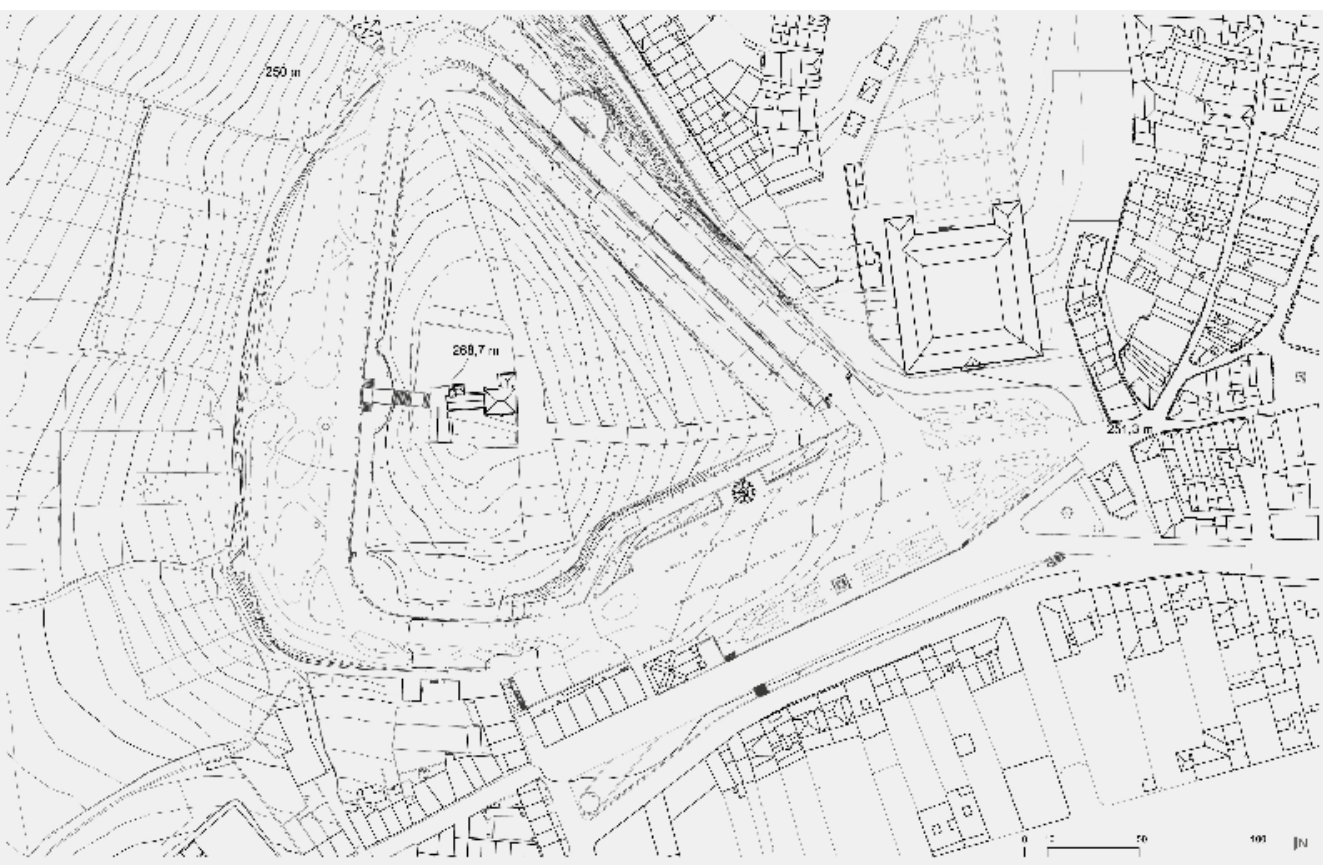

Fig. 8. Reconstrucción del entorno de Santa Susana en 1908, antes de la Exposición Regional de 1909. Enfrentada a la puerta Real del Colegio se encuentra la estatua de Figueroa.

mentos a Méndez Núñez, Rosalía de Castro y Pais Lapido, o la localización de la fuente que anteriormente se encontraba en la plaza de abastos, en el paseo de Buena Vista.

En 1908 se realizó una construcción permanente en el Paseo con destino a Pabellón de Recreo, proyectado por A. Palacios, y promovida por la Sociedad de Recreo Artístico e Industrial de Santiago. La licencia la solicitó el presidente de la Sociedad y fue concedida con la condición de que tras diez años y previo pago de una indemnización, el Ayuntamiento se quedase con el edificio ${ }^{52}$. Se construyó en el paseo de Bóveda (o de Buena Vista), cerca del Pilar, junto a la rampa de comunicación con el paseo de la Alameda.

El último paso en la ordenación del parque fue incluir en él la iglesia Santa Susana. Para ello en 1895 se proyectó su conexión; y en 1903, tras una propuesta más modesta, se ejecutó la escalera que aún hoy se mantiene ${ }^{53}$.
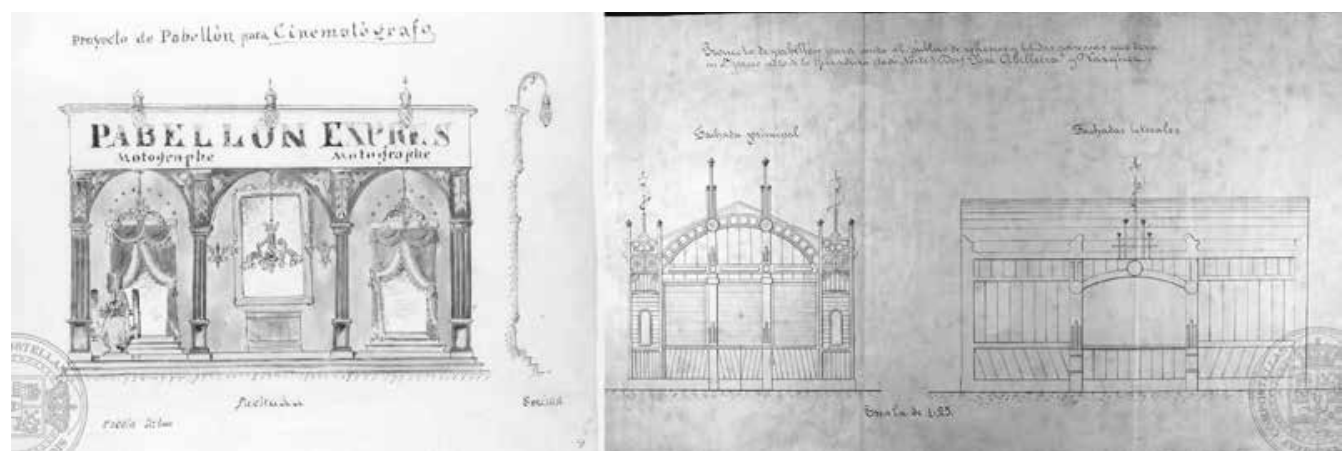

Fig. 9. Planos de construcciones temporales. Izquierda: Proyecto de cinematógrafo [AHUS A.M. 1392, p. 225r]. Derecha: Proyecto de pabellón para venta al público de refrescos y bebidas gaseosas [AHUS A.M. 588, p. 5r]. 


\subsection{Exposición Regional Gallega de 1909}

La exposición Regional de 1909 supuso la inclusión del oeste del monte en la ciudad. Ante la necesidad de un gran espacio para la exposición se pensó en los terrenos expropiados junto a Santa Susana en 1890 mencionados antes. La exposición supuso un uso temporal del lugar, pero la realización de la escalera entre el campo y el Paseo fue una unión más duradera. Con este proyecto se eliminó parte del camino que iba de Santa Susana a San Lorenzo y que aún existía en 1908 (plano de Laforet, Cánovas y de la Gándara, AHUS), borrando así la unión física entre los edificios, conectados ya sólo visualmente. El proyecto no se construyó en su totalidad por falta de medios, levantándose once de los veintisiete pabellones. También formó parte del diseño la gran escalera de unión con el Paseo de Bóveda, o de Buena Vista. La exposición se organizó en dos partes: la sección arqueológica, en San Clemente, y la sección contemporánea, construida exclusivamente para la exposición, subdividida en tres áreas, donde se incluyó el pabellón de $\mathrm{A}$. Palacios, levantado en 1908.
Para su construcción se realizó una explanada de unos diecisiete mil metros cuadrados, aproximadamente ciento cincuenta y cinco por ciento diez metros cuadrados. La conexión con el parque se realizó mediante una escalinata imperial de tres tramos que presidía el nuevo espacio, que requirió la ejecución de unos muretes en la ladera del monte creando una calle entre el parque y la exposición ${ }^{54}$, delimitando así el paseo por el oeste (Fig. 10).

Antes de la Exposición existía en la carrera de San Lorenzo una casa de baños visible desde el Paseo ${ }^{55}$, que se ha localizado gracias a la representación de una construcción en el plano de 1908. El dibujo detallado de sus jardines plantea esta posibilidad, coincidiendo su ubicación con la posible situación de la casa de baños descrita en las actas municipales (Fig. 11).

Tras la Exposición, el lugar quedó modificado y conectado con el parque. Se cree que fue en la explanada realizada para ella donde se instaló la plaza de toros, de 1915 al 35. En el proyecto de la Residencia de Estudiantes se dice que fue una "herejía urbanística que costó mucho tra-

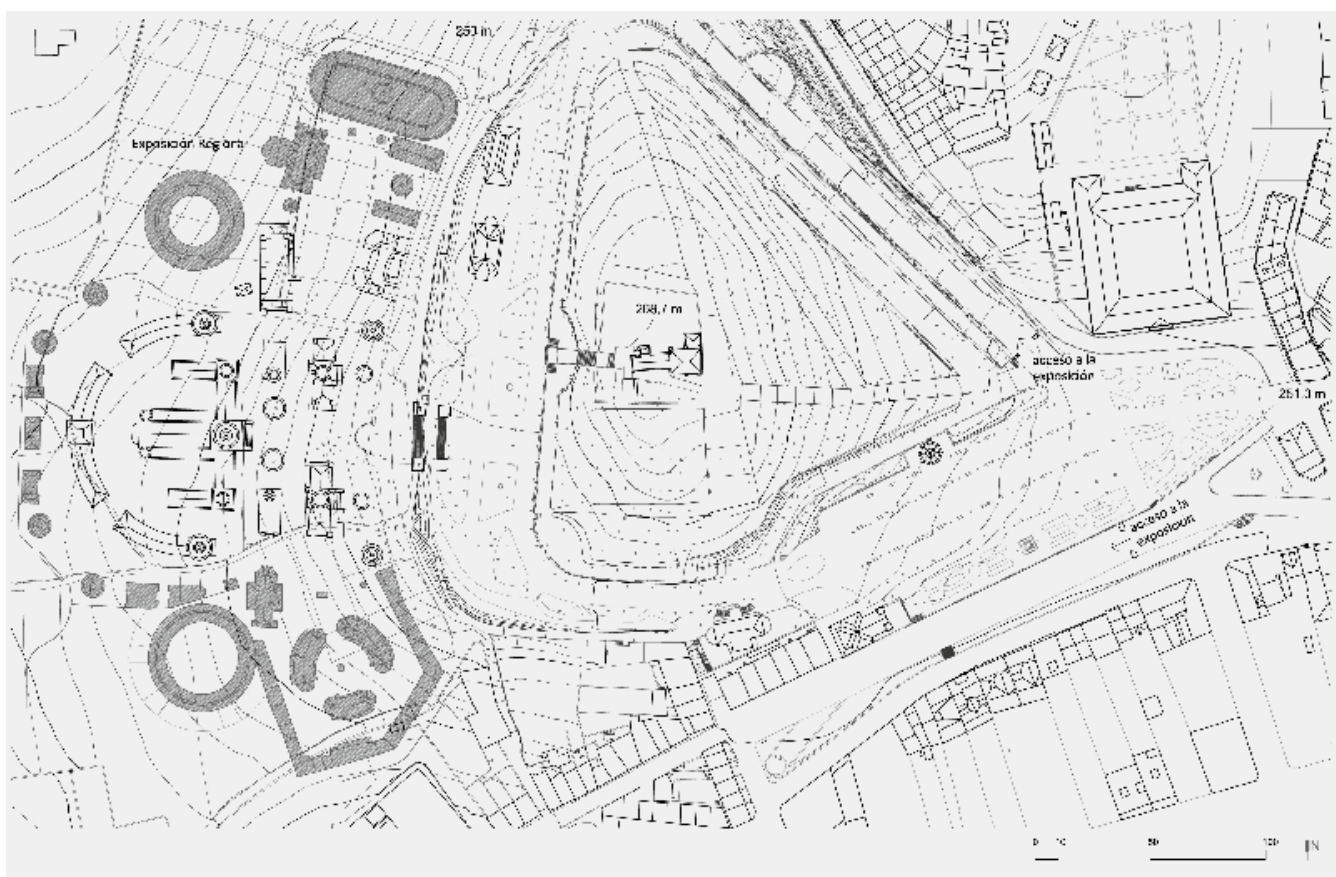

Fig. 10. Reconstrucción del plano de la Exposición Regional Gallega de 1909 localizada al oeste del monte de Santa Susana, en sombreado aparecen los elementos de proyecto que no se llegaron a ejecutar. 


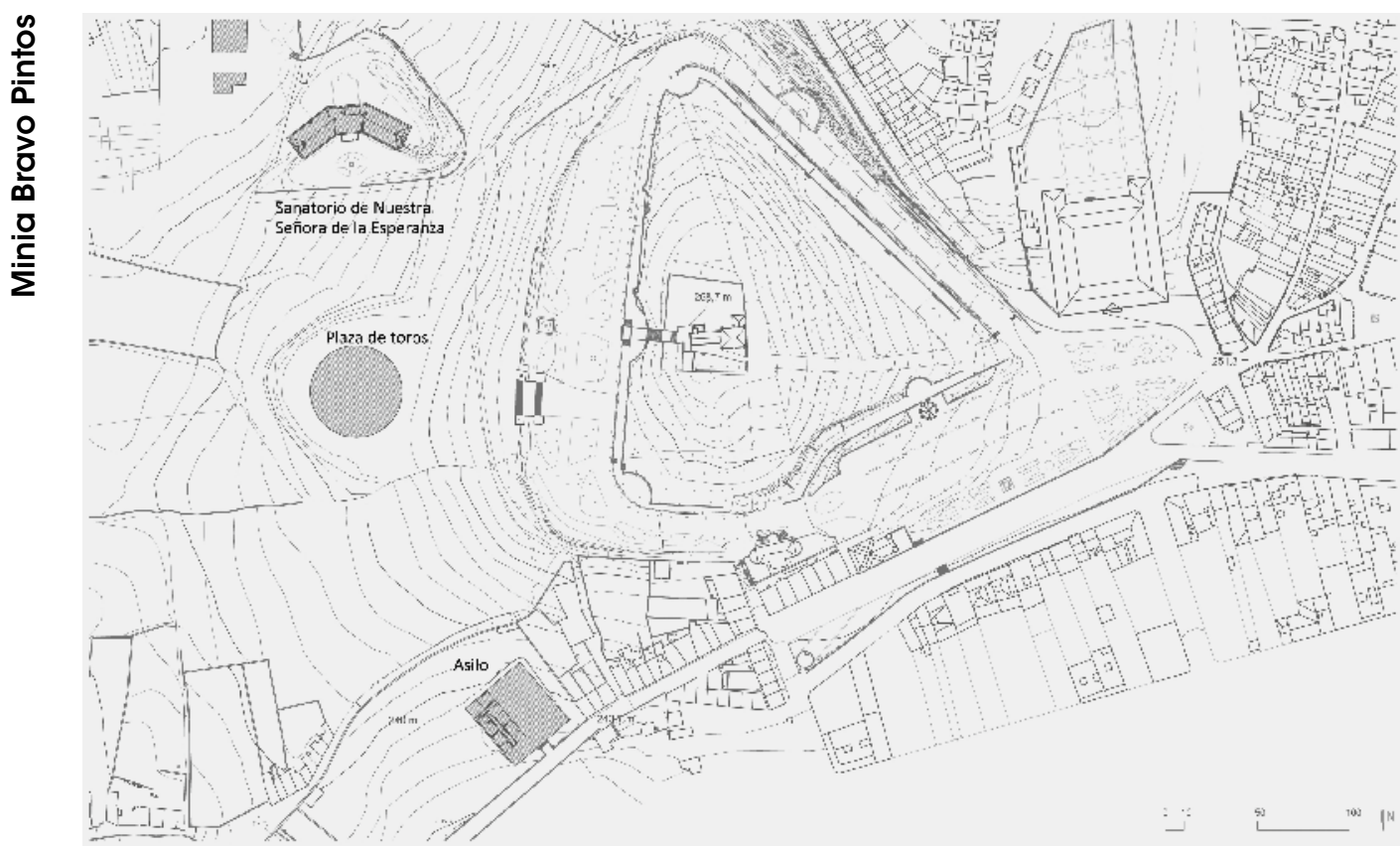

Fig. 11. Reconstrucción del plano de las edificaciones existentes a principios del siglo XX sombreadas (ca. 1920) en el Campo de Don Mendo en relación con el monte de Santa Susana.

bajo desarraigar" ${ }^{\prime \prime 5}$ y que estuvo situada entre el Paseo y el Campo de Don Mendo (Fig. 12).

A lo largo del siglo XIX y principios del XX se definió el parque de Santa Susana ya prácticamente como lo conocemos hoy ${ }^{57}$. En esta época el espacio se incorporó a Santiago y dejó de ser rural, y la ciudad se dio cuenta de que más al oeste del paseo existían terrenos interesantes para su crecimiento.

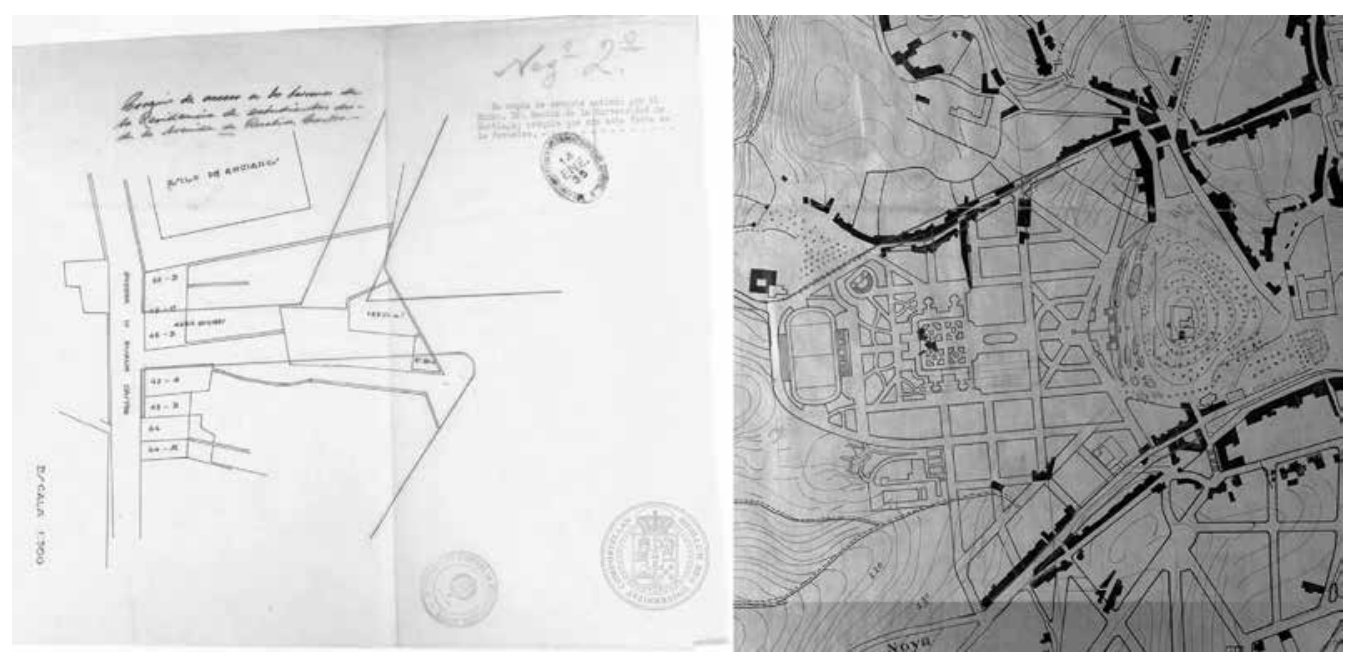

Fig. 12. Izquierda: expropiaciones para la conexión de la Residencia con la avenida de Rosalía de Castro, 1935. [AHUS A.M. 2280, Proxecto Residencia de Estudantes, exp. 6]. Derecha: vista del proyecto, sombreados los edificios existentes. [AHUS A.M. 2281, Carpeta 4, Doc. 2]. 


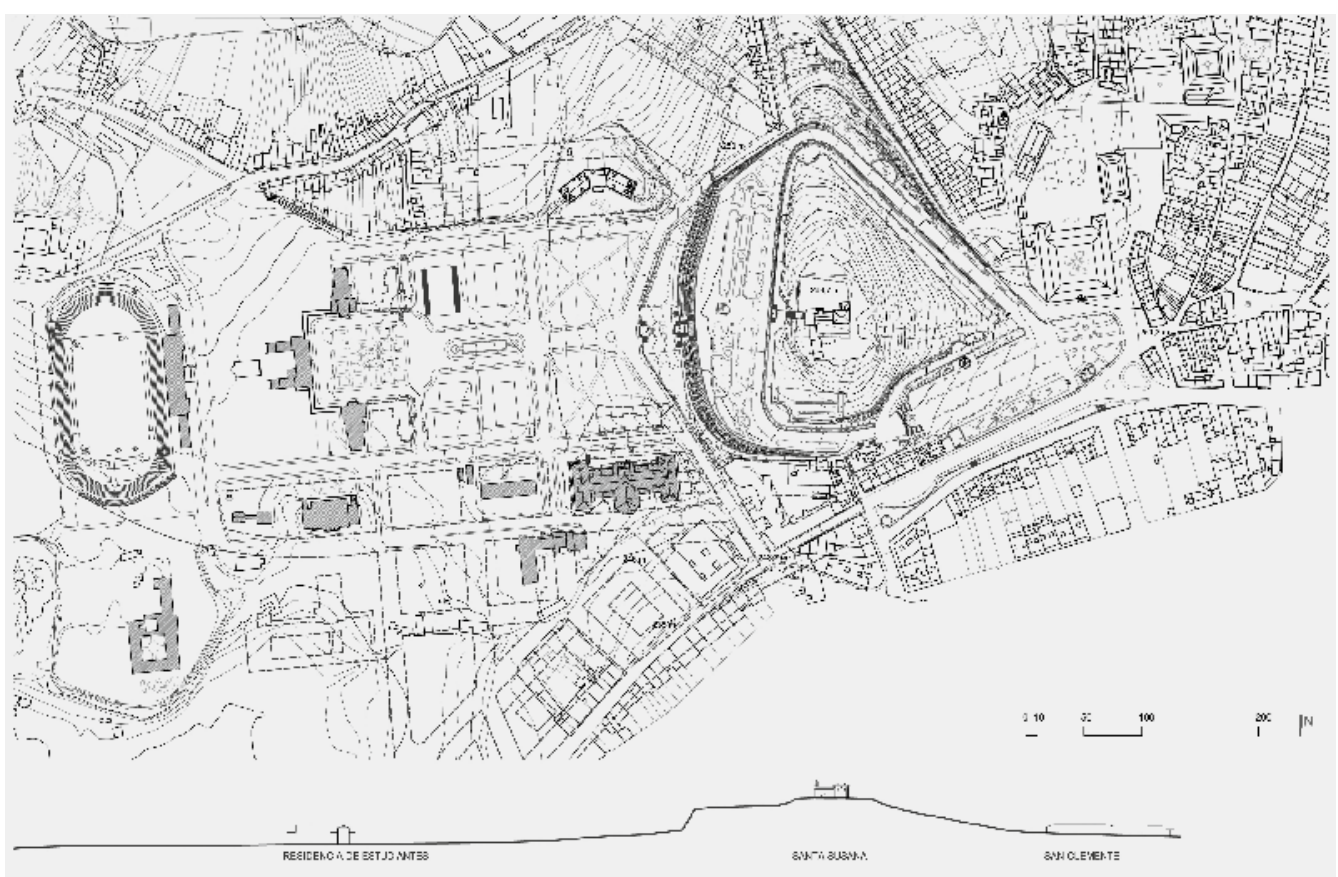

Figura 13. Proyecto de Residencia de Estudiantes, Jenaro de la Fuente, obras realizadas hasta 1956 (sombreadas). En línea de trazos la idea original de 1935. [AHUS A.M. 2280, Proxecto da Residencia de Estudantes, 1929-36].

\subsection{Campus Universitario Sur}

Tras descubrir que los terrenos al oeste del parque podían formar parte de la ciudad, en 1928 la Universidad los compró para la construcción de la Residencia de Estudiantes ${ }^{58}$. En enero de 1929 el rectorado presentó el anteproyecto de urbanización de los Agros de Don Mendo adjuntando los planos de J. de la Fuente, y entregó la Memoria general en $1930^{59}$. Dice el estudio que el proyecto "resolvía el problema en conjunto, presentando una visión completa de lo que debía ser la Residencia". Junto con la memoria se entregó el proyecto de uno de los cuatro edificios principales, solicitando el rector Cadarso licencia para su ejecución en abril de $1931^{60}$.

En 1935 la Universidad publicó imágenes del proyecto en ejecución para solicitar ayuda del Estado para que la "inversión realizada no resultase inútil" 61. En mayo de 1935, cuatro años después de comenzar las obras, se entregó el proyecto completo al Ayuntamiento, acordando éste contribuir con veinte mil pesetas. El diseño consistía en cinco edificios destinados a residencia de estudiantes, el estadio, la piscina y el teatro, completado con zonas verdes, todo ello rodeado de viviendas. La superficie proyectada fue de unos doscientos cincuenta mil metros cuadrados frente a los ochenta y un mil del parque y a los trescientos dieciséis mil del casco histórico. En abril de 1936 se aprobó el proyecto ${ }^{62}$, pero hasta 1940 no continuó su tramitación (Fig. 13). Ese mismo año se entregó un Proyecto de repoblación forestal y acondicionamiento del terreno que describía el estado de las obras ${ }^{63}$. En 1941 se puso en funcionamiento el alumbrado de la Residencia retomando así su construcción y su uso tras la Guerra Civil64. Ahora ya no sólo se planteaba como lugar de dormitorio, sino que se incluyeron las facultades en las zonas inicialmente proyectadas como "de tránsito", respetando el trazado del viario propuesto.

Durante estos años el parque de Santa Susana sufrió pequeñas modificaciones pero sin sufrir cambios sustanciales.

En los años 50, 60 y 70 del siglo XX la ciudad de Santiago experimentó un gran crecimiento, 
expandiéndose fundamentalmente hacia el sur, al tiempo que se seguía edificando la Residencia. Esto provocó que el monte de Santa Susana quedase situado en una posición central.

\section{CONCLUSIONES}

Santa Susana es un espacio con valor propio que debe ser considerado de gran importancia para la identidad cultural de Santiago. Se trata de un ámbito que no sólo posee edificios de interés sino donde el propio espacio se ha transformado en patrimonio al poseer huellas de prácticamente todos los siglos desde su transformación en monte de Santa Susana en 1105. En él se pueden ver las huellas de las diferentes maneras de aproximarse al espacio. Aunque la configuración actual se debe básicamente a los siglos XIX y XX, las actuaciones anteriores fueron las que condicionaron el lugar.

El parque, que incluye el Campo de la Estrella, el Paseo de la Herradura y la Carballeira de Santa Susana, es el resultado de un trabajo continuo donde han quedado huellas de los diferentes proyectos. En el siglo XVIII nació su valor patrimonial, valorándose el espacio en sí mismo. Aunque antes ya poseía elementos importantes, como Santa Susana, el Pilar, San Clemente, o el camino medieval, no fue hasta este siglo cuando el valor pasó de estar puntualmente distribuido a estar contenido en el espacio.

El monte de Santa Susana, de origen exterior a la ciudad, adquiere en el siglo XX una nueva centralidad sirviendo de nexo entre las diferentes tramas urbanas existentes, Ciudad Histórica, Ensanche y Campus Universitario Sur. Tras los repetidos intentos para urbanizar el monte, finalmente en el siglo XIX se descubre el espacio como lugar, con un valor patrimonial diferenciado del de su entorno, consiguiendo así que su percepción cambie, pasando de ser un ámbito sobre el que proyectar el crecimiento de la ciudad, a ser un ámbito a respetar que ya pertenece a la ciudad.

\section{NOTAS}

AGRADECIMIENTOS. Al Dr. Soraluce Blond por sus comentarios durante la elaboración del trabajo.

1 E. Falque Rey, Historia Compostelana, AKAL, 1994.

2 E. Falque Rey, op. cit. En un "suburbio de la ciudad se reedificó la Iglesia del Santo Sepulcro, ennoblecida (...) por el venerable cuerpo de Santa Susana".

${ }^{3}$ Archivo Histórico de la Universidad de Santiago de Compostela (en adelante AHUS): A.M., Gobierno, Consistorios, Libro de actas 5, 1560-1565: Folio 170: "que los pobre enfermos que se encuentran por las calles se lleven a la casa del Outeiro (Santa Susana) y se busquen mujeres que los cuiden".

Folio 266: "Empedrar la calle de las Huertas utilizando los materiales de las casas que se deshicieron en Santa Susana".

${ }^{4}$ Archivo Histórico Diocesano de Santiago. Existen registros de bautizos, bodas y funerales en Santa Susana desde finales del siglo XVI.

${ }^{5}$ AHUS, A.M., Gobierno, Consistorio, Libro de actas 14, 1625-1636, página 212: 5 de septiembre de 1630:

"A petición del Cabildo se designa una Comisión para pedir socorro ó ayuda pecuniaria a los vecinos con destino a las reparaciones de la iglesia de Santa Susana".

${ }^{6}$ Plano. 1783. J. Morenas Aydillo, "La alameda de Santiago de Compostela. Dibujos de sus arquitecturas por los alumnos de la Escuela de artes Aplicadas y Oficios Artísticos "Maestro Mateo" ". Consorcio de Santiago y Escuela de Arte "Maestro Mateo". 1994. P. 16.

7 Plano del Proyecto de reordenación del entorno de Santa Susana. J. Morenas Aydillo, La alameda de Santiago de Compostela. Dibujos de sus arquitecturas por los alumnos de la Escuela de artes Aplicadas y Oficios Artísticos "Maestro Mateo", Consorcio de Santiago y Escuela de Arte "Maestro Mateo", 1994, p 46.
El libro comenta que podría ser de 1950. La representación del proyecto, realizada sobre la base del plano de 1908 de Laforet, Cánovas y de la Gándara, está actualizada al momento del proyecto representándose los nuevos elementos del parque, aunque no el banco acústico, construido en 1916. Por ello se plantea que esta propuesta se feche entre 1908 y 1915.

8 En 1964 se volvió a plantear la integración de Santa Susana en el paseo mediante la intervención de Pons-Sorolla. B. M. Castro Fernández, Francisco Pons-Sorolla y Arnau, Arquitecto-restaurador: sus intervenciones en Galicia (1945-1985). Tesis Doctoral. USC. Fecha lectura: 4/5/2007.

Las últimas intervenciones realizadas fueron tres, dos llevadas a cabo por J. L. Pérez Franco, en 1998 y 2009; y la tercera en 2003 por J. Barata Martínez. Expediente 1998/203 de 6 de mayo, y expediente 2009/002 de 14 de julio, ambos de Patrimonio, Consellería de Cultura e Deporte, Xunta de Galicia. 
9 J. García Oro, Galicia en los siglos XIV y XV (II), Fundación "Pedro Barrié de la Maza, 1987.

${ }^{10}$ AHUS A.M., Gobierno, Consistorios, Libro de actas 4, 1542-1554, p. 219.

${ }^{11}$ Resumen de usos del monte de Santa Susana. Información extraída de documentación del AHUS, fondo municipal del Ayuntamiento de Santiago, A.M. Gobierno.

- Fuente de materias primas, desde 1546 hasta el siglo XVIII,

- Lugar de culto, desde 1105 hasta la actualidad,

- Lugar de ocio, celebración de las fiestas del Apóstol, dese 1568 hasta la actualidad,

- Usos residuales de la ciudad,

- Matadero, 1552

- Lugar improvisado para el cuidado de pobres enfermos, 1563

- Feria, desde 1552-1971

- Corral para meter los puercos, 1565-1568

- Manceba, 1565-1568

- Funciones penales, horca, intermitentemente en la Edad Media y en la época Moderna,

- Lugar defensivo y de reuniones extramuros, planos de 1595,

- Camino Real de comunicación con la ciudad de Pontevedra, punto de entrada de mercancías,

- Lugar de celebración de ferias y comercio, desde 1552 a 1971,

- Prohibición de construir en la puerta Faxeira en 1675.

12 AHUS A.M., Gobierno, Consistorio, Libro de actas 6 1565-1568, p. 382. Primera referencia del uso de feria del año 1568.

AHUS A.M., Gobierno, Consistorio, Libro de actas 9 1583-1588, p. 575v: el 15 de julio de 1583: que "el portero cobre, durante la feria del Apóstol, lo que deben pagar los que venden pipas de vino y ponen tiendas en el Campo de Santa Susana y alrededor de la Puerta Fajera".

AHUS A.M., Gobierno, Consistorio, Libro de actas 9 1583-1588, p. 725.

${ }^{13}$ AHUS A.M., Gobierno, Consistorio, Libro de actas 4 1542-1554, p.
431. En 1552 se decidió que se "haga matadero en las casas de Santa Susana en que solía vivir J. Gómez, que son de la ciudad".

AHUS A.M., Gobierno, Consistorio, Libro de actas $289,2^{\circ}$ cuatrimestre de 1801: Folios 151 a 173, 2 de julio: "que se saquen las estercoleras que hay en Santa Susana".

C. Rodríguez Dacal, Alamedas, Xardíns e Parques de Galicia, Xunta de Galicia, 1997, p. 123. "(...) a carballeira converteuse nun espacio de utilidades diversas entre outras Campo da Forca(...)".

${ }^{14}$ AHUS A.M., Gobierno, Consistorio, Libro de actas 5 1560-1565. P. 445. Aunque el "rastro de ganado" se celebrara todos los sábados en la plaza de Mazarelas, el 2 de diciembre de 1552 se concedió

"licencia a Mateo Garera para vender fuera de la ciudad pieles procedentes del ganado que se mató en las carnicerías".

15 AHUS A.M., Gobierno, Consistorio, Libro de actas 49, 1676. P. 251: La licencia solicitada estorbaba "al comercio y suo de las ferias que se hacen en el campo de Santa Susana" y por ello se deniega.

16 AHUS A.M., Gobierno, Consistorio, Libro de actas 7 1568-1575, p. 194. El 9 de abril de 1571 se pidió desde el Ayuntamiento que, con motivo de estar cerca de la costa la "ensenadra enemiga, los vecinos salgan al campo de Santa Susana con las armas que tuvieren".

17 Plano de Santiago. Archivo General de Simancas, MPD, 06, 107.

18 S. González García-Paz, O Colexio de San Clemente de Pasantes de Compostela, Universidade de Santiago de Compostela, 1993.

${ }^{19}$ Plano de Santiago donde aparece la parcela del colegio perfectamente delimitada. Archivo General de Simancas, MPD, 34, 021.

${ }^{20}$ AHUS A.M., Gobierno, Consistorio, Libro de actas 12, 1605-1613. Folio 99v. El 17 de marzo de 1608.

${ }^{21}$ AHUS, A.M., Gobierno, Consistorio, Libro de actas 12, 1605-1613, folio 138: el 27 de abril "desestimose pretensión de F. Muñoz acerca de un sitio que quería en la Puerta Fajera para hacer una casa".

AHUS, A.M., Gobierno, Consistorio, Libro de actas 16, 1637-1640, folio 313. El 11 de marzo de 1639 "denuncia de una obra que se ejecutaba en la Puerta Fajera junto al Peso".

22 AHUS, A.M., Gobierno, Consistorio, Libro de Actas 48, 1675, folio 49v:

${ }^{23}$ AHUS A.M., Gobierno, Consistorio, Libro de actas 60, 1687, folios 222 y 193: 31 de julio de 1687.

${ }^{24}$ J. R. Soraluce Blond, X. Fernández Fernández, Arquitecturas da Provincia da Coruña. Vol. XI: Santiago de Compostela, Deputación Provincial da Coruña, 1997, p. 166.

${ }^{25}$ Otras obras realizadas en el Pilar. AHUS A.M., Obras municipales, Licencias de obras 589, folio 154. El 22 de julio de 1910 el párroco Garabán solicitó licencia para reparar la fachada de la iglesia del Pilar. En 1954 ante la amenaza de ruina, el Ayuntamiento solicitó a la Mitra el cierre de la iglesia.

B. M. Castro Fernández, op. cit. Pons-Sorolla intervino en la iglesia en 1956, 1957 y 1960.

Expediente 98/196, Patrimonio, Consellería de Cultura e Deporte, Xunta de Galicia. En 1998 se realizó una intervención por F. Mingote Rodríguez, y en 2003 por J. Barata Martínez.

${ }^{26}$ A. Rosende, Una historia urbana: Compostela 1595-1780, Nigraterra S.L-Concellalía do Casco Histórico e Rehabilitación Concello de Santiago de Compostela, 2004, p. 72.

${ }^{27}$ Plano de F. J. Somoza y Ulloa. 1788. AHUS A.M., Gobierno, Consistorio, Libro de actas 267, 1-1-1789/306-1789, folio 8r: En él se refleja la solicitud de traslado del patio del cuartel a su parte posterior.

AHUS A.M., Gobierno, Consistorio, Libro de actas 267, 1-1-1789/306-1789. El Ayuntamiento acordó el 15 de abril de 1789 que por ahora, se suspendiese la resolución para la realización del patio.

${ }^{28}$ F. Singul, La ciudad de las luces. Arquitectura y urbanismo en Santiago de Compostela durante la ilustración, Consorcio de Santiago, 2001, pp. 139 y 59 . 
En 1753 la ciudad "ya tenía en este espacio abierto un agradable paseo, poblado de robles de dos filas a cordel y asientos de cantería".

${ }^{29}$ AHUS A.M. 1367, 1780-1900, pp. 1 a 56v: Ordenanzas y bandos de Policía urbana y buen gobierno.

Según A. Rosende estas ordenanzas pueden entenderse como el primer planeamiento de la ciudad. A. Rosende, op. cit.

${ }^{30}$ F. Singul, op. cit., p. 99.

${ }^{31}$ AHUS A.M., Gobierno, Consistorio, Libro de actas 253, 1-1-1783/304-1783, folio 25.

32 "En 1767 se acabó de delimitar su espacio (el del Obradoiro) con la construcción en su lado oeste del pazo de Raxoi". F. Singul, op. cit., p. 95.

${ }^{33}$ A. Vigo Trasancos, "El capitán general Pedro Martín Cermeño (17791790) y el Reino de Galicia. Poder, arquitectura y ciudad", SEMATA. Ciencias Sociais e Humanidades, vol. 10, 1998, pp. 171-202.

${ }^{34}$ AHUS A.M., Gobierno, Consistorio, Libro de actas 253, 1-1-1783/304-1783, folio 78.

El 30 de enero de 1783 el Comendador de Conjo pidió que "cesasen las guerras para hacer acopio de madera en otros reinos con destino a la construcción de casas en la plaza de Santa Susana", según lo dispuesto por el Gobernador.

35 Plano de López Freyre. 1796. Archivo del Ayuntamiento de Santiago.

36 Plano AHUS A.M., Gobierno, Consistorios, Libro de actas 289, $2^{\circ}$ cuatrimestre de 1801, folio 35r. El plano iba acompañado a una solicitud para mover un puesto. No se ha encontrado una leyenda, ni explicación, ni autoría, sobre el trazado representado con un tono rojizo.

${ }^{37}$ J. Morenas Aydillo, op. cit., p. 21.

38 Plano de B. Galiano "proyecto de paseo" de Santa Susana. 1831. J. Morenas Aydillo, op. cit., p. 20.

${ }^{39}$ M. Barral Martínez, "La Alameda, el Paseo de la Herradura y otros jardines, espacios vertebradores de la estructura social y urbana de Santiago, siglo $X I X$ y $X X^{\prime \prime}$, en Estudios en homenaje al profesor José M. Pérez García (María López Díaz, ed.), Universidade de Vigo, 2009, Vol. 1, pp. 67-76.
${ }^{40}$ C. Rodríguez Dacal, op. cit., pp. 131-132.

"En el Cuaderno de la Composición de la Alameda y Planteo de Árboles en el Campo de Santa Susana, por Disposición del llustre Ayuntamiento de esta Ciudad, que da principio hoy, 9 de febrero de 1835, dátase con precisión o comezo da construcción e menciónanse distintas especies de árbores(...) dos que os álamos resultan ser os máis copiosos(...)".

${ }^{41}$ AHUS A.M. 1391, parques e xardíns "Paseos y Arbolado Alameda antecedentes varios de los años 1835 a 1896", folios 2 al 28.

Vista del acceso oeste de la ciudad de Santiago realizada por R. Gil Rey, fechada en 1832 (Consorcio de Santiago). No estaría bien datada ya que en ella aparece representada la portada de los leones, cuando según las actas no se construyó hasta 5 años después, en 1837.

$42 \mathrm{~J}$. Morenas Aydillo, op. cit., 27.

${ }^{43}$ Plano del campo de Santa Susana, realizado por el jardinero municipal A. Barreiro Rato. 1879. J. Morenas, op. cit., p. 29.

44 AHUS A.M. 1391, Parques e xardíns, "Paseos y arbolado. Alameda antecedentes varios de los años 1835 a 1896", folios 137 a 153, y folios 200 a 202 .

F. Fernández Sánchez y Freire Barreiro, Guía de Santiago y sus alrededores. Primera edición 1885. Imprenta del Seminario Conciliar, (Reed. Santiago, 2001).

1885. El paseo de Buena Vista es un "espacio demasiado reducido para las muchísimas personas que recorren sus calles ú ocupan sus rústicos asientos (...), mientras la música del hospicio toca variadas y escogidas piezas." El monte es "una pintoresca loma, cubierta de añosos robles".

45 AHUS A.M. 1391, Parque e xardíns. "Paseo y arbolado. Alameda, antecedentes varios de los años 1835 a 1896", folios 207 a 246. Con el proyecto del nuevo cierre, redactado por M. Pereiro, se trasladaron las puertas de los leones a su posición actual, marcando la entrada del Paseo de Bóveda.

46 AHUS A.M. 1392, Parque e xardíns. "Paseo y arbolado. Alameda, antecedentes varios de los años 1835 a 1896", folio 122.

${ }^{47}$ AHUS A.M. 1390, Fuentes, folios 30r a 31r, y 37r a 55r. Folios 60r a $79 \mathrm{v}$. Las obras se concluyeron el 14 de julio de 1899.

Plano de D. García Vaamonde. Transformación de los jardines enfrentados a San Clemente para albergar la estatua de Figueroa. 1898. J. Morenas Aydillo, op. cit., p. 32

${ }^{48}$ AHUS A.M. 1392, Paseos y arbolado, antecedentes varios 1840 a 1901, folios 221 a 222.

49 J. L. Pérez Franco, Parque de Santa Susana. Plan Director de usos, Consorcio de Santiago, 2000.

${ }^{50}$ AHUS A.M. 1392: Paseos y arbolado antecedentes varios 1840 a 1901: folios 223 al 226.

${ }^{51}$ AHUS A.M. 588, Obras Municipales, Licencias de obras, 1909. Folio 1. La licencia se le concedió por 5 años.

52 P. Costa Buján, J. Morenas AydiIlo, Desenvolvemento urbano. Outra arquitectura. Santiago 1850-1950, COAG. 1989. En 1916 el pabellón fue cedido al Ayuntamiento, antes de que transcurriesen los diez años programados en la licencia.

$53 \mathrm{~J}$. Morenas Aydillo, op. cit.

${ }^{54} \mathrm{H}$. Albarellos, Centenario de la Exposición Regional Gallega. Santiago, 1909, Albarellos Editora, 2009.

${ }^{55}$ AHUS A.M. 589, Obras municipales, Licencias de Obras, folio 93, 11 de mayo de 1910. Reconstrucción de muro de cierre terreno que circunda la Casa de Baños en la Carrera de San Lorenzo, licencia solicitada por López de Rego, concedida el 28 de mayo. En la concesión se dice que, al ser un sitio visible desde el paseo de la Herradura, se debía arreglar para que su apariencia fuese la adecuada a las vistas desde el paseo.

${ }^{56}$ AHUS A.M. 2280, Proxecto da Residencia de Estudantes, 1929-36, expediente 5 y 12. La construcción de la plaza de toros se realizó en parte con fábrica de piedra, por lo que se supone que no fue concebida como una construcción temporal.

57 J. L. Pérez Franco, op. cit. En 1916 se realizó un proyecto de banco acústico. Y en 1917 se realizó el grupo escultórico de Rosalía de Castro. 
${ }^{58}$ AHUS A.M. 2280, Proxecto de Residencia de Estudantes, expediente 20. Se compraron con la ayuda de las Diputaciones y Ayuntamientos Gallegos, entidades gallegas diversas de España y América, y particulares.

${ }^{59}$ AHUS A.M. 2280, Proxecto de Residencia de Estudantes, expediente 14. Memoria general referente al anteproyecto total de la residencia de estudiantes en Santiago de Compostela.

60 J.A. Sánchez García, "El Patrimonio Arquitectónico. De la Reforma de Montero Ríos al Estatuto de Autonomía" en El Patrimonio Histórico de la Universidad de Santiago de Compostela. Vol. I. Estudios (Vila Jato, M.D. Coord.). Parlamento de Galicia-Universidade de Santiago, 1996, pp. 56-79.

${ }^{61}$ AHUS A.M. 2280, Proxecto Residencia de Estudantes. Se solicitó una ayuda de 900.000 pts., para poder continuar con las obras que se habían visto forzados a parar.

${ }^{62}$ Acuerdo publicado en el BOP de La Coruña número 212, de 18 de septiembre de 1940. Viendo el tiempo transcurrido entre la aprobación por el Ayuntamiento y la publicación en el $\mathrm{BOP}$, se ve cómo la Guerra Civil para- lizó la construcción y tramitación de la Residencia.

${ }^{63}$ AHUS A.M. 2280, Proxecto Residencia de Estudantes, expediente 15. En el "Proyecto de repoblación forestal y acondicionamiento del terreno" se explica que el edificio "Rodríguez Cadarso" estaba en funcionamiento, y en construcción su edificación gemela; la escalinata monumental (que sustituía a la de 1909 desplazada al norte); el estadio y los campos de tenis.

${ }^{64}$ AHUS A.M. 2280, Proxecto Residencia de Estudantes, 1929-36, expediente 7 . 